\title{
Tuning the Charge Carrier Dynamics via Interfacial Alloying in
}

\section{Core/Shell CdTe/ZnSe NCs}

\author{
Sourav Maiti ${ }^{\dagger \ddagger}$, Tushar Debnath ${ }^{\dagger \S}$, Partha Maity ${ }^{\dagger \S}$ and Hirendra N. Ghosh ${ }^{* \dagger}$ \\ ${ }^{\dagger}$ Radiation and Photochemistry Division, Bhabha Atomic Research Centre, Mumbai 400085, India \\ ${ }^{\ddagger}$ Department of Chemistry, Savitribai Phule Pune University, Ganeshkhind, Pune 411007, India \\ ${ }^{\S}$ Homi Bhabha National Institute, Mumbai 400094, India
}

*E-mail: hnghosh@barc.gov.in. Tel: +91-22-25593873,Fax: (+) 91-22-25505331/25505151.

(A) Absorption Spectra of all NCs from $350 \mathrm{~nm}$ to $850 \mathrm{~nm}$.

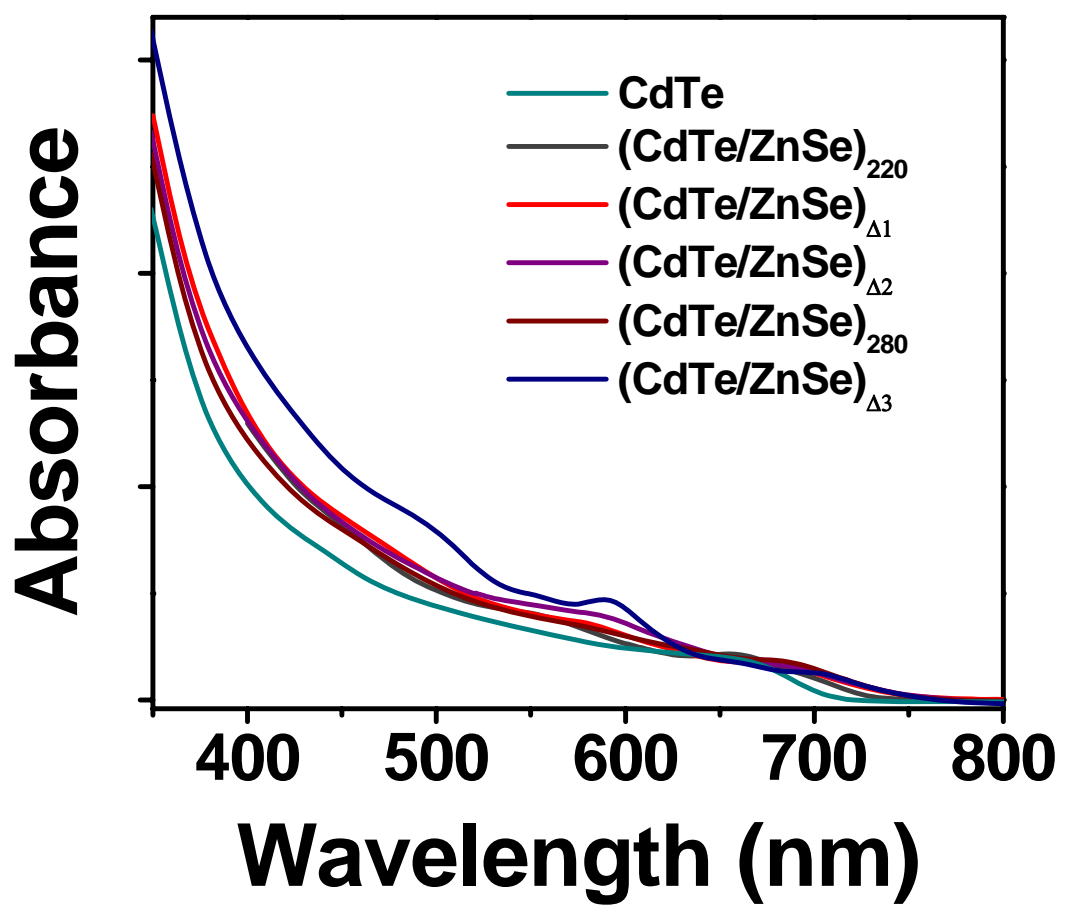

Figure S1: Uv-Vis absorption for (a) CdTe core, (b) $(\mathrm{CdTe} / \mathrm{ZnSe})_{220}$, (c) $(\mathrm{CdTe} / \mathrm{ZnSe})_{\Delta 1}$, (d) $(\mathrm{CdTe} / \mathrm{ZnSe})_{\Delta 2}$, (e) $(\mathrm{CdTe} / \mathrm{ZnSe})_{280}$ and (f) $(\mathrm{CdTe} / \mathrm{ZnSe})_{\Delta 3}$ from $350 \mathrm{~nm}$ to $850 \mathrm{~nm}$. 
(B) TEM of $(\mathrm{CdTe} / \mathrm{ZnSe})_{\Delta 3}$
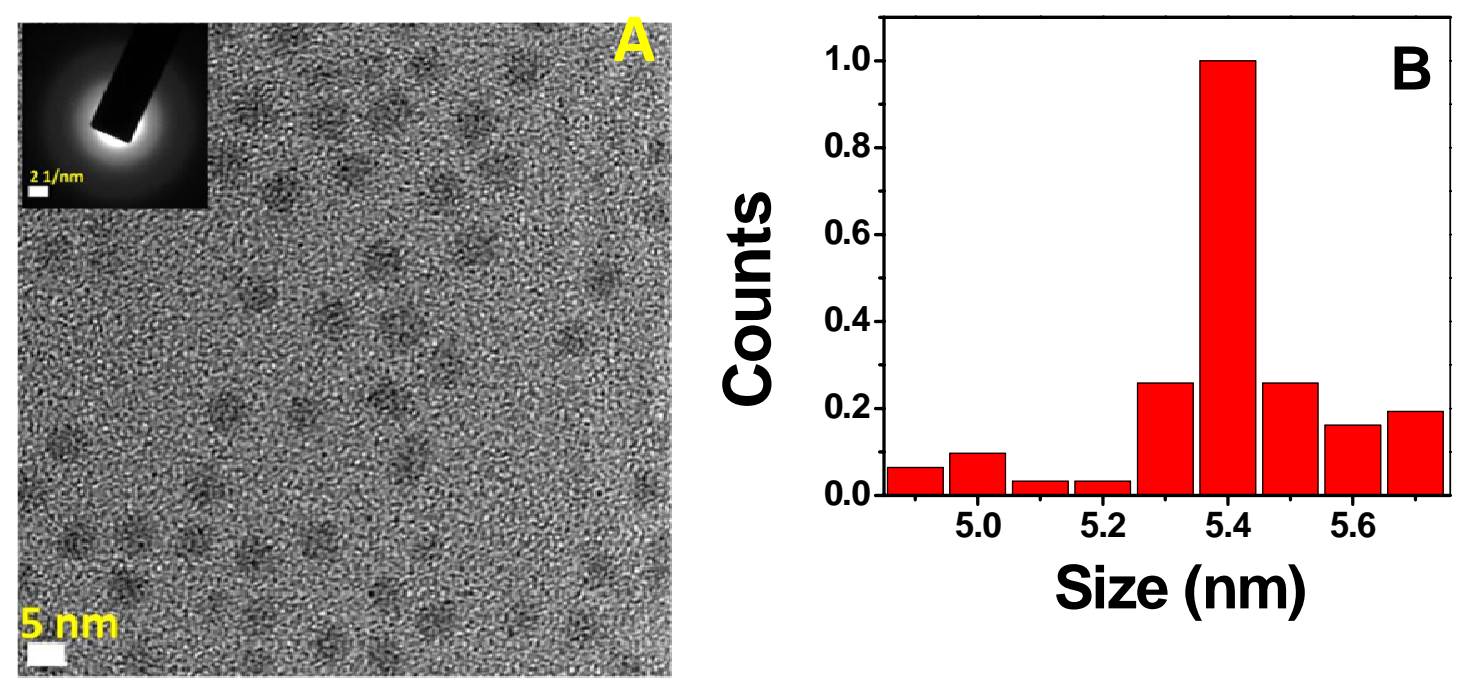

Figure S2: (A)Transmission electron micrograph (TEM) of $(\mathrm{CdTe} / \mathrm{ZnSe})_{\triangle 3}$ showing spherical shape and mono-dispersed size of the NCs. (inset) SAED pattern of the NC. (B) The size distribution of the $\mathrm{NC}$ showing monodispersed size distribution. The size of $(\mathrm{CdTe} / \mathrm{ZnSe})_{\triangle 3}$ is $5.39 \mathrm{~nm}( \pm 0.2 \mathrm{~nm})$. 
(C) PLE Spectrum for $(\mathrm{CdTe} / \mathrm{ZnSe})_{\Delta 3}$.

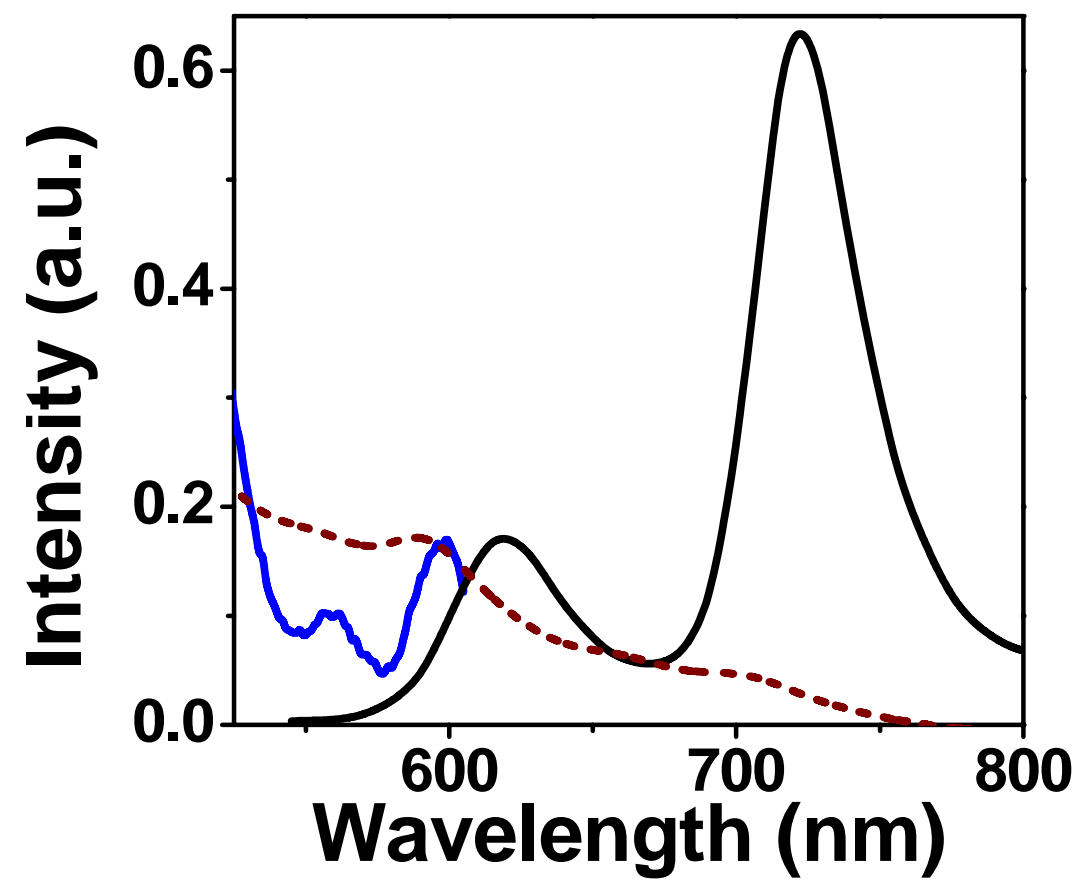

Figure S3: PLE spectrum for $(\mathrm{CdTe} / \mathrm{ZnSe})_{\Delta 3}$ (blue) plotted with the corresponding emission spectrum (black). The dashed line (wine) represents the absorption spectra. For PLE, emission was detected at $620 \mathrm{~nm}$. 
(D) TA spectra of CdTe/ZnSe NCs in $\mathrm{eV}$ scale plotted with the linear absorption spectra, inverted to match the TA spectra.
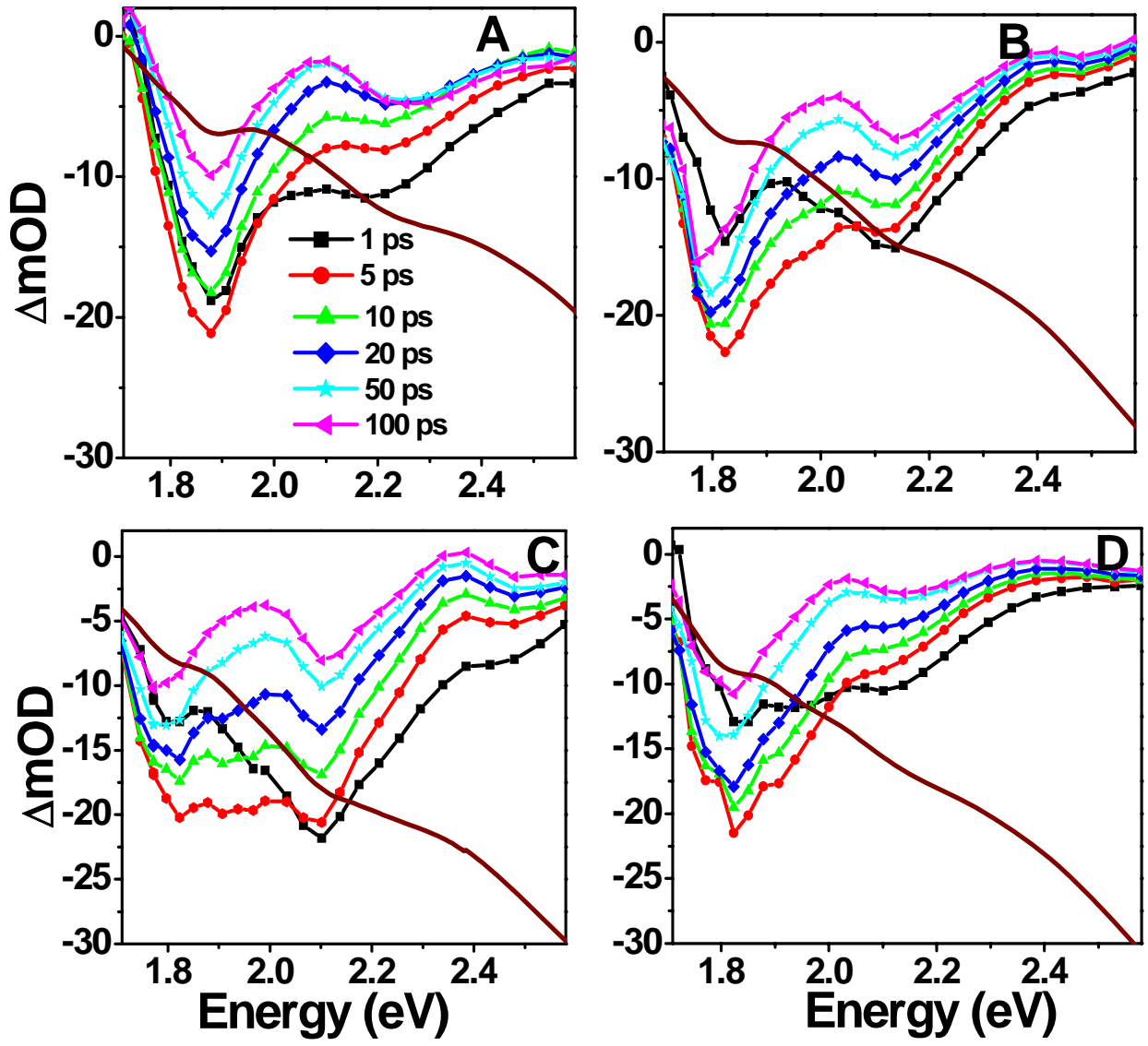

Figure S4: Transient absorption bleach spectra for (A) $(\mathrm{CdTe} / \mathrm{ZnSe})_{220},(\mathrm{~B})(\mathrm{CdTe} / \mathrm{ZnSe})_{\Delta 1},(\mathrm{C})$ $(\mathrm{CdTe} / \mathrm{ZnSe})_{\Delta 2}$ and $(\mathrm{D})(\mathrm{CdTe} / \mathrm{ZnSe})_{280}$ at different delay times after exciting the NCs at 400 $\mathrm{nm}$. The solid line in wine color shows the linear absorption spectra, inverted to match the TA spectra. 
(E) Kinetic Decay Traces for Core/Shell CdTe/ZnSe NCs:
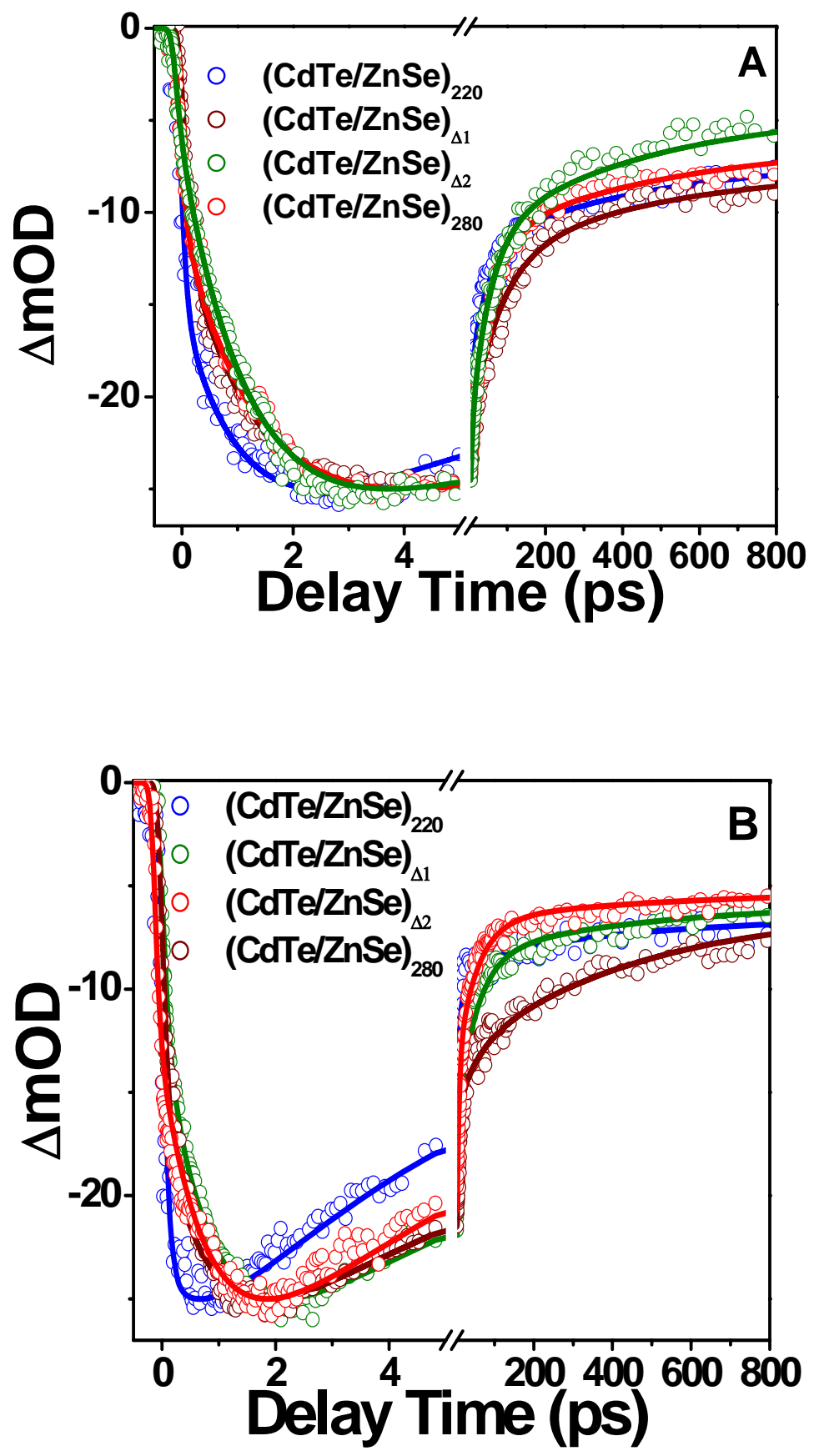

Figure S5:Kinetic decay traces (circles) along with fitted data (line) for (a) $(\mathrm{CdTe} / \mathrm{ZnSe})_{220}$, (b) $(\mathrm{CdTe} / \mathrm{ZnSe})_{\Delta 1},(\mathrm{c})(\mathrm{CdTe} / \mathrm{ZnSe})_{\Delta 2}$ and $(\mathrm{d})(\mathrm{CdTe} / \mathrm{ZnSe})_{280}$ at $(\mathrm{A}) 1 \mathrm{~S}$ and (B) $1 \mathrm{P}$ bleach positions. 
Table S1: Kinetic fitting parameters for Core/Shell CdTe/ZnSe NCs. The kinetic traces are fit with bi-exponential growth $\left(\tau_{\mathrm{g}}\right)$ and tri-exponential recovery $\left(\tau_{\mathrm{r}}\right)$ functions. The error for $\sim 1 \mathrm{ps,}$ $\sim 5$ ps and $\sim 50$ ps time constants are approximately $\pm 0.12 \mathrm{ps}, \pm 0.3 \mathrm{ps}$ and $\pm 2 \mathrm{ps}$, respectively.

\begin{tabular}{|c|c|c|c|c|c|c|}
\hline Material & $\begin{array}{c}\text { Wavelength } \\
(\mathbf{n m})\end{array}$ & $\boldsymbol{\tau}_{1}{ }^{\mathrm{g}}$ & $\boldsymbol{\tau}_{2}{ }^{\mathrm{g}}$ (ps) & $\boldsymbol{\tau}_{1}{ }^{\mathrm{r}}(\mathbf{p s})$ & $\boldsymbol{\tau}_{2}{ }^{\mathrm{r}}(\mathbf{p s})$ & $\boldsymbol{\tau}_{3}{ }^{\mathrm{r}}$ (ps) \\
\hline$(\mathrm{CdTe} / \mathrm{ZnSe})_{220 \mathrm{C}}$ & 560 & $<100 \mathrm{fs}(51 \%)$ & $0.8(49 \%)$ & $5(41 \%)$ & $50(32 \%)$ & $>400(27 \%)$ \\
\cline { 2 - 7 } & 665 & $<100 \mathrm{fs}(31 \%)$ & $1.2(69 \%)$ & $5(52 \%)$ & $50(16 \%)$ & $>400(32 \%)$ \\
\hline$(\mathrm{CdTe} / \mathrm{ZnSe})_{\triangle 1}$ & 580 & $<100 \mathrm{fs}(51 \%)$ & $0.9(49 \%)$ & $5(61 \%)$ & $50(9 \%)$ & $>400(30 \%)$ \\
\cline { 2 - 7 } & 680 & $<100 \mathrm{fs}(44 \%)$ & $1.5(56 \%)$ & $5(21 \%)$ & $75(45 \%)$ & $>400(34 \%)$ \\
\hline$(\mathrm{CdTe} / \mathrm{ZnSe})_{\Delta 2}$ & 585 & $<100 \mathrm{fs}(51 \%)$ & $1.0(49 \%)$ & $5(42 \%)$ & $50(33 \%)$ & $>400(25 \%)$ \\
\cline { 2 - 7 } & 680 & $<100 \mathrm{fs}(49 \%)$ & $1.4(51 \%)$ & $5(24 \%)$ & $75(52 \%)$ & $>400(24 \%)$ \\
\hline$(\mathrm{CdTe} / \mathrm{ZnSe})_{280 \mathrm{C}}$ & 580 & $<100 \mathrm{fs}(57 \%)$ & $0.9(43 \%)$ & $5(44 \%)$ & $50(34 \%)$ & $>400(22 \%)$ \\
\cline { 2 - 7 } & 675 & $<100 \mathrm{fs}(43 \%)$ & $1.5(57 \%)$ & $5(26 \%)$ & $50(46 \%)$ & $>400(28 \%)$ \\
\hline
\end{tabular}

\section{(F) Calculation of Number of Excitons per NC:}

All the TA experiments have carried out at $400 \mathrm{~nm}(3.1 \mathrm{eV})$ laser pulse excitation and the number of excitons $<\mathrm{N}>$ was kept $\sim 0.5$ per NC during the measurement. Therefore, we can safely rule out the bi- or multi-excitonic Auger processes that arise when $<\mathrm{N}>$ is more than 1 . We have included the following calculation of $<\mathrm{N}>$ in the supporting information following reviewer's suggestion.

$<\mathrm{N}>$ can be expressed as, 


$$
<\mathrm{N}>=\sigma . \mathrm{J}
$$

where $\mathrm{J}$ is fluence (average no. of photon $/ \mathrm{cm}^{2}$ ) and $\sigma$ is the nanocrystal surface area in $\mathrm{cm}^{2}$.

$$
\text { and } \sigma=(4 / 3) \pi \text { If } I^{2} \alpha R^{3}
$$

$\alpha$ is the bulk absorption co-efficient and $|\mathrm{fl}|^{2}$ is co-efficient for local field effect $(\sim 0.25)$.

Again, Optical Density (O.D.) $=\alpha \mathrm{c} 1$ where $\alpha$ is the absorption cross section (in $\mathrm{cm}^{-1}$ ), $\mathrm{c}$ is the concentration of the $\mathrm{NC}$ and 1 is the pathlength.

Here, O.D. 0.1(at $400 \mathrm{~nm}$ laser excitation wavelength)

$1 \sim 0.1 \mathrm{~cm}$

and conc. of nanocrystal, $\mathrm{c} \sim 10 \mu \mathrm{M}$

Therefore, $\alpha \sim 10^{5} \mathrm{M}^{-1} \mathrm{~cm}^{-1}$

$\mathrm{NC}$ size $\sim 5 \mathrm{~nm}$.

So radius, $\mathrm{R}=2.5 \mathrm{~nm}$.

therefore, $\sigma \sim 1.6 \times 10^{-15} \mathrm{~cm}^{2}$

If $\mathrm{n}$ no. of photons is falling on $\mathrm{NC}$ for $0.1 \mu \mathrm{J}$ excitation energy then,

$$
\mathrm{nh} v=0.1 \times 10^{-6} \mathrm{~J}
$$

$\mathrm{h}=6.626 \times 10^{-34} \mathrm{~J} \mathrm{~s}$ and $\quad \mathrm{v}=\mathrm{c} / \lambda=\left(3 \times 10^{8} \mathrm{~ms}^{-1}\right) /\left(400 \times 10^{-9} \mathrm{~m}\right)$

Hence, $\quad \mathrm{n} \sim 2 \times 10^{11}$

Considering beam size $\sim 300 \mu \mathrm{m}$, J becomes of the order of $\sim 2.8 \times 10^{14} \mathrm{~cm}^{-2}$

Using value of $\sigma$ and $\mathrm{j},<\mathrm{N}>$ is calculated to be $\sim 0.5$ for $0.1 \mu \mathrm{J}$ pump excitation energy. 